\title{
A importância da articulação família e escola na formação do aluno em uma perspectiva da Educação do Campo
}

\author{
The importance of Family and school articulation in students training from a perspective of Fiel
}

\author{
Education
}

\section{La importancia de la articulación familiar y escuela en la formación del alumno em una perspectiva de Educación de Campo}

Recebido: 14/03/2021 | Revisado: 20/03/2021 | Aceito: 22/03/2021 | Publicado: 31/03/2021

\author{
Sandra Nogueira Flores \\ ORCID: https://orcid.org/0000-0002-0209-849X \\ Instituto Federal de Educação, Ciência e Tecnologia Baiano, Brasil \\ E-mail: sandrafla6@hotmail.com \\ Rogério Soares Cordeiro \\ ORCID: https://orcid.org/0000-0003-0682-3182 \\ Instituto Federal de Educação, Ciência e Tecnologia Baiano, Brasil \\ E-mail: rogerio.cordeiro@ifbaiano.edu.br
}

\begin{abstract}
Resumo
O objetivo geral da pesquisa foi analisar a articulação família e escola em uma perspectiva da Educação do Campo (EC) e suas implicações na formação do aluno. Para tanto, teve participação da diretora, docentes e comunidade escolar, representada por mães e pais de alunos, todos do município de Serra do Ramalho-BA, Brasil. A metodologia orientou-se pelos princípios da abordagem qualitativa com o estudo de caso, com informações coletadas por meio de dois questionários e análise do Projeto Político Pedagógico (PPP). Os resultados indicam relações positivas, apontadas, especialmente por respeito e harmonia. Mães e pais procuram participar da vida escolar dos filhos, informação endossada pelos docentes, que apontam para necessidade de maior investimento nesse processo, desde que sejam explicitados os papéis de cada. As evidências também indicam ganhos, por parte dos alunos, nas famílias cuja participação é mais incisiva no acompanhamento escolar e tomada de decisões da escola. Por fim, propõe-se uma efetiva relação dialógica, por meio de uma série de ações que atendam as singularidades da comunidade campesina, bem como sua história de luta e trajetória de conquistas.
\end{abstract}

Palavras-chave: Educação campesina; Participação familiar; Movimentos educacionais.

\begin{abstract}
The general aim of this research was to analysis the articulation between family and school in a perspective of a Field Education and its implications for the education of students. For this, the director, teachers and school community participated, represented by mothers and fathers of students, all from the municipality of Serra do Ramalho-BA, Brazil. The methodology was guided by the principles of the qualitative approach with the case study, with information collect through two questionnaires and analysis of the Pedagogical Political Project (PPP). The results indicate positive relationships, pointed out, especially out respect and harmony. Mothers and fathers seek to participate in their children's school life, information endorsed by the teachers, who point to the need for greater investment in this process, as long as the roles of each one are made explicit. The evidence also indicates gains, on the part of students, in families whose participation is more incisive in school monitoring and school decision-making. Finally, it proposes na effective dialogical relationship, through a series of actions that meet the singularities of the peasant community, as well as its history of struggle and trajectory of conquests.
\end{abstract}

Keywords: Peasant education; Family participation; Socioeducational movements.

\section{Resumen}

El objetivo general de la investigatión fue analizar la articulación entre família y escuela en uma perspectiva de Educación Rural y sus implicaciones en la educación del alumno. Para ello, participaron el director, docentes y comunidad escolar, representados por madres y padres de alumnos, todos del municipio de Serra do Ramalho-BA, Brasil. La metodología se guió por los princípios del enfoque cualitativo com el estúdio de caso, con información recolectada a través de dos cuestionarios y análisis del Proyeto Político Pedagógico (PPP). Los resultados indican relaciones positivas, señaló, especialmente por respeto y armonía. Madres y padres buscan participar em la vida escolar de sus hijos, información avalada por los docentes, quienes señalam la necesidad de uma mayor inversión em este proceso, simpre que se expliciten los roles de cada uno. La evidencia también indica avances, por parte de los 
estudiantes, en famílias cuya participación es más incisiva em el monitoreo escolar y la toma de decisiones escolares. Finalmente, propone una relación dialógica efectiva, a través de uma serie de acciones que responden a las singularidades de la comunidade campesina, así como a su historia de lucha y trayectoria de conquistas.

Palabras clave: Educación campesina; Participación familiar; Movimientos socioeducativos.

\section{Introdução}

As relações estabelecidas entre escola e família sempre ocuparam um espaço importante de discussão, especialmente no que tange o desenvolvimento educacional dos alunos, considerando que essas duas esferas são as principais responsáveis pela formação integral do sujeito. Escola e família cumprem papéis distintos, mas complementares. O ambiente familiar é o primeiro lugar de socialização, e será nele que o sujeito conhecerá os valores e saberes que conduzirão ao longo da vida.

A escola também se encontra submersa na tarefa de educar. É por meio do trabalho pedagógico que a integração entre os dois ambientes deve ter como princípio o desenvolvimento cognitivo e social da criança. De tal modo, o processo educacional não acontece apenas em um espaço, os sujeitos aprendem em contato com o outro e com o meio social. O sujeito quando chega ao espaço formal de ensino já possui experiências e conhecimentos, fruto da sua vivência em contato com a família e com os amigos, ou seja, com o seu mundo de vida.

Para tanto, é importante que haja uma interação entre as partes, uma complementando a outra, considerando assim aspectos importantes da vida da criança. Entretanto, por muito tempo, prevaleceu a ideia de que, à escola, incumbia apenas a tarefa de transmitir ao aluno os saberes científicos e normas de conduta dentro do seu meio social; à família, o papel de transmitir valores e regras de bom comportamento. Desse modo, havia uma separação entre a vida cotidiana das crianças e os momentos na escola, uma vez que, pouco se considerava, na educação formal, os conhecimentos prévios dos alunos.

Escola e família são instituições sociais que estão sempre presentes na vida do ser humano, de forma que ao pensar o aluno no seu contexto é preciso que as duas partes estabeleçam uma relação de parceria. Assim, partindo da proposição que a participação da família na escola possibilita um melhor desempenho escolar das crianças, esta pesquisa buscou analisar qual a influência que uma parceria efetiva entre família e escola tem no processo de formação do sujeito e, mais especificamente, em uma escola do campo.

Ao buscar compreender os problemas existentes no campo, é necessário salientar o processo histórico da educação no Brasil, marcado pela discriminação e segregação dos grupos sociais mais necessitados, mesmo que as constituições brasileiras tenham aumentado o ingresso à educação em todos os níveis, da alfabetização ao ensino superior.

Diante dessa realidade, ao discutir essa relação no contexto da Educação do Campo, que será aqui tratada como EC, é necessário abordar, a princípio, a visão do que a escola representa para essa comunidade, partindo do pressuposto que a escola é também uma representação da luta desses sujeitos na busca do reconhecimento dos seus direitos.

A escola do campo, em algumas comunidades, além de ser espaço de aquisição de saberes, é o lugar onde a mãe leva seu filho para ser atendido pelo médico; pesado pela pastoral da criança; vacinado; inscrito em projetos governamentais, como a aquisição de cisternas e de poços artesianos, por exemplo; além de reunião de associações; celebrações de missas, dentre outros acontecimentos.

O despertar para este estudo surge nas discussões calorosas na faculdade de pedagogia e durante as aulas da pósgraduação de especialização em EC. A busca de um novo paradigma, que nos oportunize lidar com problemas reais como os propostos pela sociedade de hoje, tornou-se o eixo norteador na decisão de pautar a presente pesquisa, sobre a parceria escolafamília na EC. A necessidade de investigar percursos que auxiliem na relação vivida atualmente pelas escolas e famílias é visível diante de diversos desafios que as duas organizações enfrentam no desenvolvimento do processo educacional do aluno.

Considerando as variáveis supracitadas, esta pesquisa teve objetivo central analisar a articulação família e escola em uma perspectiva da EC e suas implicações no desempenho escolar. Este objetivo geral se desdobra em três específicos: i) 
identificar a complexa relação entre escola e família no processo de formação do sujeito; ii) analisar sobre a influência da contribuição quando existente da parceria entre a escola e a família com o desenvolvimento educacional dos estudantes e iii) traçar possibilidades para que escola e família possam estabelecer uma relação de parceria efetiva no processo educacional.

Nesse contexto, este estudo torna-se relevante por discutir concepções e propostas que abarcam a importância da construção de uma parceria efetiva entre escola e os desafios e possibilidades existentes na consolidação dessa articulação uma escola situada no campo. De maneira reflexiva, as considerações feitas sistematizam a compreensão sobre as duas instituições mais importantes no processo de socialização e educação do sujeito.

\section{Educação do campo: um conceito em construção}

Ao empreender uma discussão sobre a educação voltada ao povo do campo é necessário abordar, a princípio, as diferenças entre educação rural e EC. A educação rural é uma educação comprometida com a reprodução do método de conservação da ordenação instituída, da falta de território do campesinato e da dependência ao capital, pois, essa modalidade de ensino tem como princípios a lógica do capital e do agronegócio (Ribeiro, 2013).

Em contraposição a essa educação, surgiu o movimento por uma EC. Segundo Caldart (2008), essa nova concepção é fundamentada no movimento camponês, e tem com o objetivo construir uma educação humana e emancipatória, ligada à vida, ao trabalho, à cultura, e aos saberes das práticas sociais dos camponeses, buscando promover assim a formação global do sujeito. A distinção entre EC e educação rural mostra as complicações desta última em termos do entendimento da pluralidade das lutas e dificuldades presente no contexto do meio rural (Fernandes, 2009). Enquanto a EC é compreendida como lugar de resistência, criador de vida e cultura, a educação rural está ligada a uma percepção mais mecânica e, por isso, pouco engajada na busca de solução para oriundos dessa localidade.

Assim, EC tal qual conhecemos, é fruto de uma longa trajetória de lutas, visto que a educação destinada ao povo do campo, ao longo da história da educação brasileira desde a colonização, tem sido interposta por uma tendência de condutas sociais de exclusão, refletidas ao longo da coordenação da educação brasileira e seus métodos de ensino, sustentando por muito tempo apenas um padrão de ensino, o urbano (Arroyo, 1982).

"Em nossa história domina a imagem de que a escola do campo tem que ser apenas a escolinha rural das primeiras letras. A escolinha cai não cai, onde uma professora que quase não sabe ler ensina alguém a não saber quase ler" (Arroyo, 1999, p. 20, grifo nosso). Ainda nesta descrição, acrescenta-se que "[...]as escolas implantadas no campo só contribuíram para reforçar essa imagem. Escolas com pedagogias bancárias, importadas da cidade: currículo, calendário, cartilha e professor" (Coelho, 2011, p. 136).

No entanto, apesar da demanda inerente de propostas para a EC, somente após a criação da LDB 9394/96 (Brasil, 1996) foram abertos precedentes legais, jurídicos e políticos para a possibilidade da implantação de uma educação que respeitasse a identidade do homem e da mulher do campo. A lei supracitada propõe em seu Art. 28, que o processo de ensino desenvolvido no campo deve respeitar as singularidades existentes neste espaço de formação, sendo obrigatória a adaptação de um currículo com especificidades para estas demandas. Entretanto, apenas a regulamentação desse artigo não abarcou os anseios e as necessidades do povo campesino.

Foi por meio da atuação dos movimentos sociais, que em 1998, surge a Articulação "Por uma EC", entidade que passou a promover e gerir ações conjuntas pela escolarização dos povos que representam este espaço em nível nacional. Dentre as diversas conquistas a partir dessa articulação, destaca-se a aprovação, em 2002, da resolução CNE/CEB n 01 de 03 de abril que estabeleceu as Diretrizes Operacionais para a Educação Básica nas Escolas do Campo, o Parecer CNE/CEB nº 1/2006, que trata dos dias Letivos para a aplicação da Alternância nos Centros Familiares de Formação por Alternância; a Resolução CNE/CEB n. 02, de 28 de abril de 2008, que estabelece diretrizes complementares, normas e princípios para o 
desenvolvimento de políticas públicas de atendimento da Educação Básica do Campo. Em 2010, foi aprovado o decreto 7352 que dispõe sobre a política de educação do campo e o Programa Nacional de Educação na Reforma Agrária (PRONERA).

Isso mostra que a luta dos movimentos sociais e das entidades civis em prol da construção de uma nova concepção de educação do campo se fortaleceu e ganhou forma ao longo do tempo. Não admitindo mais uma concepção simplória de educação, como a que acha que para a escola do campo não é necessário muito, afinal "para mexer com enxada não precisa de muitas letras" (Arroyo, 1999, p. 11). O autor ainda endossa que a luta pela EC vai muito além da mera formação de mão de obra, visam à concretização de direitos, de homens, mulheres, jovens, crianças que devem ser vistos pela escola, pelo professor não como um número ou mais um aluno apenas, mas como gente, como pessoa com especificidades, história, diferenças (Arroyo, 1999). Neste sentido, destaca-se:

"A educação do campo nasceu também da crítica a uma educação pensada em si mesma ou um abstrato; seus sujeitos lutaram desde o começo para que o debate pedagógico se colasse a uma realidade, de relações sociais concretas, de vida acontecendo em sua necessária complexidade" (Fernandes, 2002, p. 72).

Ainda nesse escopo:

"A educação do campo se identifica pelos seus sujeitos: é preciso compreender que por trás da indicação geográfica e da frieza de dados estatísticos está uma parte do povo brasileiro que vive neste lugar e desde as relações sociais específicas que compõem a vida no e do campo" (Caldart, 2002, p. 27).

No recorte, compreende-se que a EC envolve um vasto processo que consiste na luta pela valorização da cultura e da identidade do homem e da mulher do campo, tendo na educação um meio para alcançar novos horizontes e caminhos. Partindo de um projeto pedagógico feito com o povo do campo, acrescentando todas as vivências dos atores dessa história.

Ao estudar sobre EC é possível compreender que o próprio conceito está em construção, entendendo que a denominação da expressão EC é mais política do que realmente etimológica, visto que se faz por meio da resistência e de luta.

O conceito de educação do campo é novo, mas já está em disputa, exatamente porque o movimento da realidade que ele busca expressar é marcado por contradições sociais muito fortes. Para nós o debate conceitual é importante à medida que nos ajuda a ter mais claro quais são os embates e quais os desafios práticos que temos pela frente. No debate teórico o momento atual não nos parece ser o de buscar "fixar" um conceito, fechá-lo em um conjunto de palavras: porque isso poderia matar a idéia de movimento da realidade que ele quer apreender, abstrair, e que nós precisamos compreender com mais rigor justamente para poder influir ou intervir no seu curso (Caldart, 2008, p. 12).

Pensada sob essa perspectiva a EC revela sua complexidade, mas esse conceito relacional é necessário devido ao fato desta ser concebida como espaço de luta, de formação de identidades e de militância na reivindicação de formação política dos sujeitos do campo. A construção identitária do povo do campo pressupõe o reconhecimento desse povo como sujeito, ator de sua história e, como tal, possuidor de direitos.

\section{Família e escola: uma abordagem histórica e conceitual}

A relação entre educação e família é histórica e remonta às sociedades primitivas, onde as novas gerações educavamse no cotidiano por meio da observação das atividades de seus pais e dos anciãos da comunidade; nesse contexto, o ato educativo era regido pelo trabalho, pela necessidade de aprender a maneira de produzir a subsistência de sua futura família e na observação das atitudes dos mais velhos (Durkheim, 1978).

Segundo Ariès (1981), a família contemporânea, formada por pai, mãe e filhos, foi organizada a partir de diversas alterações da percepção religiosa e política, em que somente depois de muito tempo passou a valorizar o seu conceito, como o 
próprio da infância. No Brasil, a concepção de família possuiu diferentes abordagens. Na Constituição Federal de 1967, antes do governo democrático, o artigo 167 abordava que "a família é instituída pelo casamento" (Brasil, 1967). Após a publicação da Constituição Federal de 1988, no artigo 226, a imagem de família foi ampliada e passou a ser entendida como "o grupo formado por qualquer dos pais e seus filhos" (Brasil, 1988).

No dicionário Aurélio (2018), família é definida como grupo de pessoal que compartilham a mesma casa [...] pessoas que possuem relação de parentesco [...] estabelecida pelo casamento, por filiação ou pelo processo de adoção. Partindo de uma visão contemporânea o conceito se amplia. Numa outra perspectiva "[...] a família é uma instituição cujas origens remontam aos ancestrais da espécie humana e confundem-se com a própria trajetória da evolução" (Osório, 1996, p. 24). Com o passar dos anos as configurações familiares mudam e ressignificam.

Nesse contexto, é imprescindível reconhecer as novas configurações que aconteceram no ambiente familiar, uma vez que a família tradicional, composta de pai, mãe e filhos está exposta aos dinamismos de mudança. Há algum tempo, os papéis do pai e da mãe, dentro do contexto familiar eram bem definidos; hoje, pai e mãe, assumem diversas funções conforme os contextos que permeiam a vida em sociedade. Sobre essas novas organizações do modelo familiar, Battagllia (2002) assinala:

"Como construções sociais relativamente recentes, estas complexas reformulações familiares encontram-se sem modelo preestabelecido. Sendo assim, cada família necessita lidar com seus padrões e conceitos preestabelecidos para deles fazer emergir uma maneira original de constituir um grupo familiar com funções, direitos e deveres que atendam aos que dele participam" (Battaglia, 2002, p. 7).

A família realiza papel fundamental no desenvolvimento natural e social dos indivíduos, visto que o sujeito passa por três etapas de socialização: a primária, que é desenvolvida no ambiente familiar; a secundária, que é a definida na escola durante o processo educacional; e, por fim, a terciária que é a que acontece no meio social em que a pessoa vive. Para que haja maior clareza:

"Como primeira mediadora entre o homem e a cultura, a família constitui a unidade dinâmica das relações de cunho afetivo, social e cognitivo que estão imersas nas condições materiais, históricas e culturais de um dado grupo social. Ela é a matriz da aprendizagem humana, com significados e práticas culturais próprias que geram modelos de relação interpessoal e de construção individual e coletiva" (Dessen; Polonia, 2007, p. 22).

Em consonância com essa questão, Parolin (2008) reforça que a família cumpre, até então, o papel de intermediária entre a criança e a sociedade, viabilizando a sua socialização. Assim, durante muito tempo, a responsabilidade de educar as crianças era exclusivamente da família, no ambiente familiar aprendiam-se costumes, regras e normas da cultura.

No entanto, com o passar dos anos e com as mudanças nas dinâmicas sociais, surgem novas intersecções na relação família e escola. Diante dessa realidade, a escola surge como um lugar onde as famílias podiam deixar seus filhos para que tivessem acesso ao processo de ensino.

De acordo com Castro e Regattiere (2009), após a instituição da República no Brasil em 1889 foi que a escola passou a ter como configuração o modelo que conhecemos atualmente. Esse novo molde foi considerado essencial para a construção da sociedade. Segundo as autoras, nesse período houve "um aumento na importância da escola primária que teve como contraponto a desqualificação das famílias para a tarefa de oferecer a instrução elementar, progressivamente delegada à instituição escolar, cujos profissionais estariam tecnicamente habilitados para isso" (Castro; Regattiere, 2009, p. 21).

No ano de 1988 é criada a Constituição Federal do Brasil e, com ela, a escola passa por novas transformações, os objetivos dessa Carta Magma são detalhados na LDB 9394/96, assim imbuída dos processos cíveis define educação em seu art. $1^{\circ}$ como: 
Art. $1^{\circ} \mathrm{A}$ educação abrange os processos formativos que se desenvolvem na vida familiar, na convivência humana, no trabalho, nas instituições de ensino e pesquisa, nos movimentos sociais e organizações da sociedade civil e nas manifestações culturais (Brasil, 1996).

De acordo com a Constituição Federal de 1988 e a LDB 9394/96, família e escola são parceiras fundamentais na criação e elaboração de ações que podem favorecer o sucesso escolar e social das crianças, ao organizar uma relação efetiva, possibilita que as duas partes compartilhem das mesmas regras e princípios, de modo que todos busquem a mesma direção em relação aos objetivos que desejam obter (Brasil, 1996).

No entanto, Nogueira (2006) ressalta que essa relação sempre teve uma ênfase maior em procurar culpados pelos desafios enfrentados no processo de ensino aprendizagem, do que na construção de uma parceria voltada a resolver as situações-problema que ocorrem no contexto escolar, de forma conjunta.

De um lado, a escola é idealizada como apenas um lugar de transmissão de conteúdo, colocando a família como única responsável pela formação social e cultural da criança; por outro lado, a família deixa a cargo da escola toda responsabilidade educacional do aluno, desde a construção de valores até a aprendizagem dos saberes institucionalizados.

\section{Percurso Metodológico}

\section{Lócus e os sujeitos da pesquisa}

A pesquisa foi realizada na escola Marcos Freire, fundada em 1997 e situada na cidade de Serra do Ramalho, sudoeste da Bahia, no Vale do São Francisco, $845 \mathrm{~km}$ de Salvador. A comunidade é composta por pessoas que receberam lotes de terras distribuídos pelo INCRA situada à margem da BR 349. Conhecida como Comunidade Social Beneficente (CSB), este grupo de pessoas assentadas se dedicam à agricultura, com culturas anuais, e à criação de ovelhas e porcos, também com algumas famílias dedicando-se à criação de gado.

Na escola, no ano de 2020, foram matriculados 93 alunos, estes, oriundos da comunidade CSB, da Vila Formosa e do Projeto Formoso. É recorrente que atenda aos discentes de famílias que vêm trabalhar nos lotes de produção de banana nas adjacências. O turno de funcionamento é matutino, das $07 \mathrm{~h} 30$ às $11 \mathrm{~h} 30$, com os segmentos de Educação Infantil, das Séries Iniciais do Ensino Fundamental e $6^{\circ}$ ano das séries finais do Ensino Fundamental. No que cerne ao quadro de servidores, a instituição possui uma diretora, um auxiliar administrativo, duas auxiliares de serviços gerais, uma merendeira, um vigilante e oito professoras.

Participaram da pesquisa, de forma espontânea, um total de 19 pessoas. Dentre estes, foram inclusos a diretora e docentes, o que corresponde a 26,32\%. A comunidade escolar, representados por mães e pais dos alunos, correspondem 73,68\%. A escolha partiu da necessidade de compreender, na prática, a realidade da relação entre escola e família na educação e sua implicação no processo de ensino-aprendizagem dos estudantes.

Como previamente referido, a participação foi voluntária e espontânea, respeitando às premissas éticas, o espaço de cada sujeito ou de cada parte que participa da ação, de maneira livre e natural. Para Cenci (2000), os princípios éticos recomendam: liberdade de participar ou não da pesquisa, tendo como garantia, sem quaisquer retaliações atuais ou futuras, de que não há identificação e que se manterá o caráter confidencial das informações relacionadas com a privacidade; liberdade de acesso aos dados do estudo em qualquer etapa da pesquisa e segurança de acesso aos resultados da mesma.

\section{Questionários e análise das informações}

Para se entender, como se dá a relação das famílias com a escola, foi proposto um questionário constituído por nove questões abertas que partiram da identificação dos participantes e, finalmente, sobre os aspectos mais relacionais entre estes (Quadro 1). 
Quadro 1 - Dimensões e categorias do questionário aplicado às mães, pais e/ou responsáveis.

\begin{tabular}{|l|l|ll|}
\hline \multicolumn{4}{|c|}{ Identificação } \\
\hline ITEM & DIMENSÃO & VARIÁVEIS \\
\hline 1 & Gênero & ( ) masculino( ) feminino( ) outros \\
\hline 2 & Escolaridade & $\begin{array}{l}\text { ( ) analfabeto } \\
\text { ( ) ensino fundamental completo } \\
\text { ( ) ensino médio completo } \\
\text { () ensino superior completo }\end{array}$ & $\begin{array}{l}\text { ( ) ensino fundamental incompleto } \\
\text { ( ) ensino médio incompleto } \\
\text { () ensino superior incompleto } \\
\text { () outros }\end{array}$ \\
\hline 3 & Qual série/ano estuda o aluno (a) que você é responsável? \\
\hline 4 & Qual o seu grau de parentesco com o aluno? \\
\hline 5 & \multicolumn{2}{|c|}{ Relação família e escola } \\
\hline 6 & Como é a relação entre família e escola? \\
\hline 7 & $\begin{array}{l}\text { Como é a sua participação nas reuniões e/ou eventos organizados pela escola? } \\
\text { Quando não participam qual o motivo? }\end{array}$ \\
\hline 8 & $\begin{array}{l}\text { Você participa do processo de ensino e aprendizagem da criança? } \\
\text { Se sim. De que forma acontece essa participação? }\end{array}$ \\
\hline 9 & Qual a sua visão sobre a importância da família no processo de ensino e aprendizagem? \\
\hline
\end{tabular}

Fonte: Autores (2021).

Ainda com foco nos colaboradores da pesquisa, um segundo questionário foi proposto. Neste, tencionou-se entender as relações entre a gestão escolar, constituída por direção, coordenação e docentes, juntos à comunidade. Este instrumento foi composto por 12 questões do tipo abertas (Quadro 2).

Quadro 2 - Dimensões e categorias do questionário aplicado à equipe gestora da escola e aos docentes.

\begin{tabular}{|c|l|l|}
\hline \multicolumn{2}{|c|}{ Identificação } \\
\hline ITEM & \multicolumn{1}{|c|}{ DIMENSÃO } & \multicolumn{1}{c|}{ VARIÁVEIS } \\
\hline 1 & Gênero & ( ) masculino( ) feminino( ) outros \\
\hline 2 & Formação Acadêmica & ( ) graduação ( ) especialização ( ) mestrado ( ) doutorado \\
\hline 3 & Residência & ( ) zona rural ( ) zona urbana \\
\hline 4 & Cargo Ocupado & ( ) diretor ( ) coordenador ( ) docente \\
\hline 5 & Se professor, qual série/ano leciona? \\
\hline \multicolumn{2}{|c|}{ Relação gestão e família } \\
\hline 6 & Como é a relação entre escola e família? \\
\hline 7 & $\begin{array}{l}\text { Existe algum conflito/ divergência na relação entre escola e a família onde você trabalha? } \\
\text { Se sim, quais são? }\end{array}$ \\
\hline 8 & $\begin{array}{l}\text { Em sua opinião, as atividades realizadas na escola com a participação da família contribuí } \\
\text { para um melhor desenvolvimento escolar dos alunos? }\end{array}$ \\
\hline 9 & $\begin{array}{l}\text { Existe alguma diferença na socialização e aprendizagem das crianças conforme a a } \\
\text { participação da família no ambiente escolar? }\end{array}$ \\
\hline 10 & $\begin{array}{l}\text { Quais ações você desenvolve para que haja uma maior participação da família nas } \\
\text { atividades escolares das crianças? }\end{array}$ \\
\hline 11 & $\begin{array}{l}\text { A gestão escolar promove uma integração entre escola e comunidade? Se sim, de que } \\
\text { forma? }\end{array}$ \\
\hline 12 & $\begin{array}{l}\text { Quais são as estratégias que a escola poderia elaborar para que as famílias participassem } \\
\text { mais da vida escolar dos alunos? }\end{array}$ \\
\hline
\end{tabular}

Fonte: Autores (2021).

Os questionários foram disponibilizados para os sujeitos da pesquisa através do grupo de conversas do aplicativo de comunicação via celular. Este grupo foi criado pela equipe gestora da escola onde estão adicionados todos os funcionários da escola e os familiares dos alunos. 


\section{O estudo de caso como estratégia de pesquisa}

A metodologia de uma pesquisa nasce com a definição do problema, visto que cada área do conhecimento exige uma maneira diferente de manusear os conhecimentos. Isso caracteriza a definição do problema como algo decisivo para traçar os rumos da pesquisa, já que a metodologia, como já mencionado, é traçada de modo a atender os objetivos e a intenção do pesquisador.

Para tanto, durante a pesquisa, foi utilizada a abordagem qualitativa, que possibilita ao pesquisador conhecer os fenômenos estudados em sua essência, bem como penetrar no universo pesquisado e extrair daí as informações que o levarão a entender e interpretar esses fenômenos, bem como, responder à indagação que originou a pesquisa. Nesse sentido, "possui a facilidade de poder descrever a complexidade de uma determinada hipótese ou problema, analisar a interação de certas variáveis, compreender e classificar processos dinâmicos experimentados por grupos sociais" (Oliveira, 1999, p. 117).

Nessa perspectiva, a abordagem qualitativa permite compreender o porquê de uma situação, por meio da análise dos significados que os sujeitos atribuem aos fatos inerentes ao fenômeno estudado. Neste estudo, a pesquisa de cunho qualitativo, assegura ao pesquisador conhecer qual a visão da escola e da família sobre o seu papel na educação das crianças, a concepção de participação familiar no cotidiano escolar; como também conhecer e entender os significados que os pais atribuem à relação família-escola e a influência, ou não, dessa relação na aprendizagem do aluno.

Por se tratar de um estudo que parte de alguns pressupostos teóricos iniciais, mas procura manter constantemente atentos a novos elementos emergentes e importantes para discutir a problemática em questão, o que tipifica o estudo de caso. De acordo com uma definição:

"um estudo de caso é uma investigação empírica que: investiga um fenômeno contemporâneo dentro de seu contexto da vida real, especialmente quando os limites entre o fenômeno e o contexto não estão claramente definidos" (Yin, 2005, p. 32).

O momento pandêmico causado pela Covid-19 ocasionou várias mudanças em todos os setores da sociedade e, no meio acadêmico, não foi diferente. Previamente, a estratégia seria a pesquisa-ação. No entanto, devido às normas estabelecidas de distanciamento social, deu-se a alteração. Ressalta-se que todas as etapas da pesquisa foram realizadas à distância, mediada por aplicativos de comunicação.

O estudo de caso possibilitou aprofundar sobre o entendimento de conceitos e discussões de estudos sobre a relação escola e família especificamente, no contexto da EC. Quanto aos tipos foi exploratório e descritivo. Exploratório, pois almejou aprofundar e aperfeiçoar ideias e teve como "objetivo proporcionar maior familiaridade com o problema, com vistas a torná-lo mais explícito ou a constituir hipóteses" (Gil, 2002, p.41) e descritivo, pois se constituiu em um estudo de determinado fenômeno, tendo como foco "primordial a descrição das características de determinada população ou fenômeno ou, então, o estabelecimento de relações entre variáveis" (Gil, 2002, p. 42).

Segundo Ludke e André (1986), a pesquisa qualitativa demanda que a escolha dos instrumentos e técnicas de coleta de informações sejam as mais adequadas à natureza do tema. Neste contexto, os procedimentos para coleta de informações escolhidas foram o questionário e análise documental. O questionário é um instrumento de pesquisa que permite obter informações baseando-se, geralmente, na indagação de um grupo exemplar da população em análise. Sobre essa técnica de pesquisa, o autor aponta que "a construção do questionário consiste basicamente em traduzir os objetivos específicos da pesquisa em itens bem redigidos" (Gil, 1987, p. 126).

A segunda técnica utilizada foi análise documental, que ao constituir como uma técnica utilizada na coleta de informações qualitativas pode complementar as evidências obtidas por outras técnicas a partir da análise e interpretação de elementos contidos em documentos. De acordo com Oliveira (1999), os documentos são registros escritos que contém 
informações em prol da concepção dos fatos e relações, ou seja, permitem conhecer o período histórico e social das ações e reconstruir os acontecimentos e seus antecedentes, pois consistem em manifestos registrados de contextos da vida social de um determinado povo.

Por se tratar de uma pesquisa que apresenta como um dos objetivos traçar possibilidades para que escola e família possam estabelecer uma relação de parceria efetiva, foi realizada uma análise documental no Projeto Político Pedagógico (PPP) da escola, com o intuito de identificar se o documento é munido de proposições que fomentem atividades integrativas.

\section{Análise dos resultados}

Após a coleta das informações por meio de instrumentos e técnicas de pesquisa, o investigador tem diante de si a tarefa de organizar as informações coletadas para realizar uma análise e reflexão de maneira crítica e sistemática. Assim,

A análise tem como objetivo organizar e sumarizar os dados de tal forma que possibilitem o fornecimento de respostas ao problema proposto para investigação. Já a interpretação tem como objetivo a procura de sentido mais amplo das respostas, o que é feito mediante sua ligação e outros conhecimentos anteriormente obtidos (Gil, 1999, p. 168).

Nesse tipo de análise, o trabalho do pesquisador, vai além do tratamento das categorias fundantes ou informações, pois o ato de transformar em texto, por meio da interpretação, tudo o que foi dito e ouvido, conduz o pesquisador no caminho de volta ao momento da coleta de informações.

Nesse sentido, após a análise, na etapa da construção desse trabalho, deve ser feita a triangulação das informações, que "significa olhar para o mesmo fenômeno, ou questão de pesquisa, a partir de mais de uma fonte de dados. Informações advindas de diferentes ângulos podem ser usadas para corroborar, elaborar ou iluminar o problema da pesquisa" (Decrop, 2004, apud Abdalla et al 2013, p. 4).

Assim, é o momento da apreensão destes fenômenos que permeiam os mundos de vida dos sujeitos fundamentando-se nos autores que serviram de base para construção de um conhecimento prévio a respeito do fenômeno investigado. A triangulação possibilita o fortalecimento de nossa compreensão a respeito do fenômeno estudado, viabilizando o surgimento de novas perspectivas de estudo e percepções de análises mais profundas.

\section{Resultados e Discussão}

A análise das informações foi feita a partir dos questionários (Quadros 1 e 2). Dessa forma, as respostas foram agrupadas em quatro categorias fundantes: 1. Como acontece essa relação; 2. Construção dessa relação na EC; 3. Implicação dessa relação no desenvolvimento do processo de ensino-aprendizagem e, 4. Desafios e possibilidades para efetivação dessa relação.

\section{Os colaboradores representantes da família dos alunos}

A versão de questionário disponibilizada às famílias foi respondida por 14 pessoas e organizada de acordo com o Quadro 3. 
Quadro 3 - Descrição do perfil dos colaboradores da categoria família.

\begin{tabular}{|l|c|c|c|}
\hline Participantes & Escolaridade & Parentesco & Segmento \\
\hline A & Ensino Médio completo & Mãe & $1^{\circ}$ Jardim \\
\hline B & Ensino Médio Completo & Mãe & $5^{\circ}$ Ano \\
\hline C & Ensino Fundamental Incompleto & Pai & $2^{\circ}$ Jardim \\
\hline D & Ensino superior completo & Mãe & $6^{\circ}$ ano \\
\hline E & Ensino Fundamental Incompleto & Mãe & Maternal \\
\hline F & Ensino Fundamental Incompleto & Pai & $3^{\circ}$ ano \\
\hline G & Ensino fundamental completo & Mãe & $5^{\circ}$ ano \\
\hline H & Ensino Médio Completo & Mãe & $1^{\circ}$ Ano \\
\hline I & Ensino Médio completo & Mãe & $2^{\circ}$ ano \\
\hline J & Ensino Superior Completo & Mãe & $1^{\mathbf{o}}$ e $5^{\circ}$ anos \\
\hline K & Ensino Médio completo & Mãe & $1^{\circ}$ Jardim \\
\hline L & Ensino Superior completo & Mãe & $3^{\circ}$ ano \\
\hline M & Ensino fundamental completo & Pai & $2^{\circ}$ ano \\
\hline N & Ensino Médio completo & Mãe & $4^{\circ}$ ano \\
\hline
\end{tabular}

Fonte: Autores (2021).

Nota-se que os participantes correspondem a primeiro grau de parentesco com os alunos, sendo a maioria, representada por mães. Com esta informação inicial, percebe-se uma inclinação da manutenção da cultura de que a responsabilidade pelo acompanhamento escolar é da mulher. Sobre o grau de escolaridade, nota-se certa heterogeneidade, ainda assim, com prevalência de sujeitos cuja formação escolar é, predominantemente, ensino fundamental incompleto. De forma não intencional, os entrevistados têm filhos matriculados em todos segmentos, o que possibilita uma análise com maior diversidade.

\section{Os colaboradores pertencentes à direção e ao quadro docente escolar}

O questionário disponibilizado para os componentes da escola foi respondido por cinco pessoas, sendo que quatro são professoras e uma é diretora. Como forma de preservar a identidade dos participantes, foram propostos apelidos (Quadro $4)$.

Quadro 4 - Descrição do perfil dos entrevistados categoria escola.

\begin{tabular}{|l|c|c|c|}
\hline Entrevistados & Função & Formação & Reside \\
\hline Girassol & Professora $1^{\mathbf{0}}$ ano & Pós-graduação completa & Zona Rural \\
\hline Rosa & Professora $2^{\mathbf{o}}$ ano & Pós graduação incompleta & Zona Rural \\
\hline Margarida & Professora $3^{\mathbf{0}}$ ano & Mestrado incompleto & Zona Rural \\
\hline Violeta & Professora $6^{\mathbf{0}}$ ano & Graduação completa & Zona Rural \\
\hline Gardênia & Diretora & Pós-Graduação completa & Zona Rural \\
\hline
\end{tabular}

Fonte: Autores (2021).

\section{Escola e família: uma aproximação necessária}

Ao estudar sobre como acontece essa relação é preciso, antes de tudo, esclarecer o que se espera de cada parte nessa parceria, ou seja, é necessário definir qual são as funções da família e da escola. No artigo 205 da Constituição Federal de 1988, está posto que “A educação, direito de todos e dever do Estado e da família” (Brasil, 1988).

Partindo da visão que a escola, é a representação do Estado como instituição responsável pela educação do ser humano, a Constituição define que é dever da escola e da família promover, conjuntamente esse processo, ressaltando assim 
que as duas organizações sociais são corresponsáveis. A LDB, $n^{\circ}$ 9.394/96, assinala a necessidade dessa articulação nos seus $\operatorname{artigos} 12^{\circ}$ e $13^{\circ}$ que:

Art. $12^{\circ}$. Os estabelecimentos de ensino, respeitadas as normas comuns e as do seu sistema de ensino, terão a incumbência de:

VI - articular-se com as famílias e a comunidade, criando processos de integração da sociedade com a escola;

Art. $13^{\circ}$. Os docentes incumbir-se-ão de:

VI - colaborar com as atividades de articulação da escola com as, famílias e a comunidade (Brasil, 1996).

Segundo a LDB, a escola, ao buscar cumprir seu papel social, precisa criar ações em sua proposta pedagógica que possibilitem a integração entre família e comunidade, respeitando e reconhecendo as suas especificidades. Baseado nessas concepções, foi realizado um levantamento diagnóstico sobre a relação entre escola e família. Acerca dessas informações, apontam-se como aspectos positivos:

"Boa. A escola sempre procura manter uma boa relação com os pais e alunos. Sempre que necessário entra em contato com os pais". (Participante A).

"Muito boa" (Participante C).

"Relação de respeito, de educação!” (Participante D).

"De parceria” (Participante L).

Nos excertos, de um modo geral e, mais especificamente na fala do participante 'A', é ressaltada a importância da escola, aberta ao relacionamento por meio do diálogo com responsáveis, reconhecendo que esse contato com a família pode trazer informações sobre fatores que interferem na aprendizagem e, dessa partida, apontar caminhos mais apropriados para superá-los. Nesse sentido, Reis (2010, p. 17) afirma que a "família e escola são pontos de apoio e sustentação ao ser humano, são marcos de referência existencial. Quanto melhor for a parceria entre ambas, mais positivos e significativos serão os resultados na formação do sujeito".

Ao responder sobre essa mesma questão, as docentes entrevistadas, também sinalizaram relações mutuamente benéficas:

"Boa. A maioria dos pais sempre participa das reuniões que marcamos. A relação é dialógica e bem participativa" (Professora Girassol).

"Boa, às famílias são bem participativas" (Professora Rosa).

"Embora tenhamos alguns pais muito distantes, podemos dizer que temos uma relação harmoniosa com as famílias" (Professora Margarida).

Os depoimentos, tanto das professoras, quanto das famílias, apresentam congruências positivas. Há, portanto, um alerta da docente Margarida, que tenciona ao dizer "Embora tenhamos pais muito distantes". Trecho que pode explicitar a pouca ou baixa participação dos pais e mães no espaço da escola. Essa fala é endossada pela gestão escolar, na pessoa da diretora Gardênia "é boa, harmoniosa, mas poderia ser melhor, ainda temos algumas famílias com nível baixo de participação". 
Compreende-se, tomando como base as falas dos entrevistados, que embora haja uma relação de parceria, o processo desenvolvimento das famílias, é insuficiente. Acerca desta relação dialógica, o autor Silva (2012) alerta que, apesar de corpo docente e direção de muitas escolas reclamarem da falta de uma participação mais efetiva por parte das famílias, muitos, se mostram desconfortáveis em receber opiniões de alguns pais mais críticos, ou ainda, que questionam formas de ações pontuais.

Outro aspecto explicitado pela pesquisa foi o entendimento sobre o nível de participação das famílias na escola. Destacam-se alguns argumentos:

"Sempre que tem, eu sempre participo pra mim sempre sabe do desenvolvimento da escola e nos eventos sempre estamos marcando presença na escola todos eu participo" (Participante D).

"Sempre estou presente. Se ausente é devido o tratamento que fazemos em outro estado" (Participante G).

"Sou participativa nas reuniões e nos eventos quando eu não participo épor que estou trabalhando mais é difícil eu não participar" (Participante I).

"Participo sempre que posso" (Participante M).

Há um consenso sobre a participação das famílias junto à programação escolar. No entanto, ressalta-se o trecho “[...] é porque estou trabalhando [...]", na fala do participante I. A ocupação com o labor é mesmo um gargalo para o acompanhamento dos pais, especialmente em horário de reuniões pré-determinadas. Se são pré-determinadas é porque, com raríssimas exceções ouviram às propostas ou disponibilidade de horários pelos responsáveis. Isso evidencia, ainda mais, o apontamento de Paro (2001), quando diz que a maioria dos programas de envolvimento das famílias é mais acessível aos pais que não trabalham.

Diante desse cenário, é preciso que, ao planejar as reuniões e eventos, seja levada em consideração a realidade da comunidade em que a escola está situada. As famílias, no contexto da EC, precisam ser ouvidas. Ainda sobre a questão da participação da família no ambiente escolar, é preciso deixar claro o que se espera dessa participação.

"Será que é estar presente nas reuniões para ouvir informações burocráticas e queixas referentes ao mau comportamento dos alunos? Será que é ter acesso a decisões previamente estabelecidas? Será que é ajudar a organizar a festa junina da escola? Será que é poder ouvir e falar? Será que é a possibilidade de uma ação coletivamente construída por todas as partes envolvidas no processo ensino-aprendizagem, na qual se compartilhar equitativamente, resguardadas as particularidades dos sujeitos envolvidos, a possibilidade de planejar, decidir e agir? Enfim, muitos podem ser o significado da palavra participar" (Pequeno, 2005, p. 4).

Assim, o conceito de participação deve estar bem delineado, visto que na maioria das vezes, a participação dos pais fica restrita às ações como receber boletins com notas e faltas. Também é comum na execução de atividades e eventos como bazares e festas, mas é quase nula quando se refere à tomada de decisões da escola. Nesse sentido:

"A exigência da participação dos pais na organização e gestão da escola corresponde a novas formas de relações entre escola, sociedade e trabalho, que repercutem na escola nas práticas de descentralização, autonomia, coresponsabilização, interculturalismo. De fato, a escola não pode ser mais uma instituição isolada em si mesma, separada da realidade circundante, mas integrada numa comunidade que interage com a vida social mais ampla" (Libâneo, 2004, p. 114).

Essa participação deve ser vista como uma ampliação das possibilidades de acertos na elaboração de um processo educacional que tenha como foco o aluno reconhecendo as suas dificuldades e realçando as suas potencialidades. Desse modo, 
entende-se que família e escola constituem duas instituições sociais que partilham de uma mesma finalidade que é a educação do sujeito, no entanto, cada uma das partes tem sua própria forma de transmitir esse conhecimento, tanto social como educativo. Assim, quando ambas as partes entenderem quais são os seus verdadeiros papéis dentro do contexto escolar, a relação se estreitará, tanto uma como a outra, tem como sugerir ou questionar a participação das duas organizações na formação do aluno.

Ao ser questionado sobre quais ações a escola desenvolve para que haja uma maior participação da família nas atividades escolares das crianças, obtiveram-se os seguintes argumentos:

"Procuro sempre estar dialogando com os pais sobre o rendimento escolar dos meus alunos, incentivo eles a acompanhar os filhos em casa e sempre a estou a disposição deles quando me procura para conversar" (Professora Girassol).

"Trabalho com projetos pedagógicos que envolvem a familia ativamente, em todas as atividades propostas" (Professora Rosa).

"Eu procuro sempre passar atividades em que os pais possam ajudar os filhos a responderem" (Professora Margarida).

"Sempre ligo ou mando mensagem por telefone e whatsapp para os pais, parabenizando o filho ou convocando para reuniões ou visitas à escola" (Professora Violeta).

Tais relatos mostram que há uma preocupação por parte das docentes em estabelecer um vínculo com a família, desenvolvendo atividades voltadas à promoção da integração. No trecho "[...] mensagens por telefone e WhatsApp [...]", narrado pela professora Violeta, tem-se que, por meio das Tecnologias da Informação e Comunicação (TICs) e das redes sociais, seja propiciada mais uma estratégia de aproximação. Ressalta-se, a importância dessa correspondência, sobretudo, na possibilidade de que ambas as instituições possam compartilhar princípios educacionais buscando diminuir as prováveis diferenças. Quando se refere à relação com a família, é preciso, por parte da escola:

"Uma exposição clara para a família da filosofia da escola e de seus objetivos é de fundamental importância para que uma relação dialógica se estabeleça em base de uma aceitação de princípios de parte a parte. Isso evita muitos mal-entendidos, falsas expectativas e exigências descabíveis" (Macedo, 1998, p. 196).

Portanto, compreende-se que o diálogo entre a escola e a família seja capaz de possibilitar a troca de ideias. Em nenhuma instância compete à escola julgar como certa ou errada a educação que cada família oferece. O objetivo da escola é oportunizar e abrir espaços para que valores sejam adquiridos, bem como trabalhar o respeito e as diferenças expressas pela família, proporcionando e garantindo a integridade básica do aluno.

\section{O papel da escola e da família na construção de uma educação do campo}

Considerando que a criança é um sujeito histórico e social, que faz parte de uma organização familiar e se encontra inserida em uma sociedade com uma determinada cultura e um dado momento histórico. Um dos desafios impostos a essa nova sociedade, é o de formular e conduzir um processo de desenvolvimento educacional em que a escola possa atender a essas transformações sociais. Assim: 
"A escola continua, grosso modo, a ser considerada meramente como uma instituição acadêmica, omitindo a diversidade social e cultural que a habita e excluindo de diversas formas, os que são "diferentes". Nesta perspectiva, a problemática da relação família-escola, corresponde a uma relação multi-cultural, em última análise, a uma diversidade de modos de ser e estar" (Dias, 1996, p.2).

Isso se faz primordial, para que a escola ao cumprir seu papel social, procure conhecer as famílias dos alunos, a comunidade onde está situada, para que ao propor um trabalho em conjunto possa ao mesmo tempo retratar essa diversidade existente na configuração da EC. Desse modo, possibilitará uma formação crítica do educando, pois quando se conhece o contexto no qual o aluno está inserido, torna-se facilitada a elaboração pedagógica para que se possa aperfeiçoar o que ele conhece.

Partindo dessa reflexão, a análise sobre a relação escola e família na EC deve ter como base o conhecimento de como se desenvolveu o processo de ensino voltado aos sujeitos que vivem no campo. Ao serem questionados sobre qual é o papel da escola na educação dos alunos do campo no contexto atual, foram obtidos, das professoras, argumentos como:

"O papel da escola é em buscar valorizar os conhecimentos prévios dos alunos para que eles se sintam representados durante o desenvolvimento das aulas" (Professora Girassol).

"Propor à formação do indivíduo do campo e também sua valorização" (Professora Rosa).

"A escola tem o papel de promover uma formação global dos sujeitos, que os prepare para o mundo do trabalho e para atuar sobre sua realidade, transformando-a de maneira que seja mais sustentável e forneça uma vida digna para os mesmos. Nesse sentido, a escola não deve atuar apenas como transmissora de informações, mas como espaço de construção de conhecimento" (Professora Margarida).

"Fazer com que tenham conhecimentos significativos, capazes de refletir e compreender o espaço que estão inseridos" (Professora Violeta).

Diante das escritas docentes, percebe-se que todas reconhecem que as EC precisam ter como base um processo de ensino que reconheça e valorize a realidade do seu povo. Numa paráfrase à fala da professora Margarida, a escola ao cumprir sua função social, não pode apenas reproduzir conteúdo, é preciso ser um espaço de construção.

Nesse cenário, quando a criança ingressa na escola as diferenças socioculturais devem ser levadas em consideração e respeitadas no cotidiano escolar. O papel do professor transcende a transmissão de conteúdo, pois assume uma função social na lida com a construção de conhecimento, questionamento da realidade e formação de pessoas críticas. O centro de sua práxis deve ser o sujeito, não no sentido de depósito de informação, mas no sentido de ser possuidor de experiências e conhecimentos prévios relevantes. Ideia comungada pela diretora da escola, quando explicita que a EC precisa:

“Atuar na politização dos alunos, preparando-os para atuar no mundo do trabalho e cobrar seus direitos. Também, é papel da escola contribuir com a construção da identidade dos alunos do campo, por meio de uma prática pedagógica contextualizada com as especificidades do seu contexto sociocultural” (Diretora Gardênia).

O depoimento dialoga com a Constituição Federal de 1988 e a LDB 9394/96 sobre a preparação do aluno para o mundo do trabalho e acrescenta ainda que esse processo de formação necessita estar vinculado à sua realidade. Para tanto, a escola busca sincronizar o fazer pedagógico e a realidade do campo, o fazer administrativo com as necessidades sociais da comunidade, buscando construir um processo de ensino dentro das especificidades do contexto rural na qual está inserida. 
Em consonância com essa questão Caldart aborda que é preciso "[...] pensar a escola desde o seu lugar e os seus sujeitos, dialogando sempre com a realidade mais ampla e com as grandes questões da educação, da humanidade" (Caldart, 2002, p. 35). Assim, a educação desenvolvida nesse espaço precisa ser pensada na formação de sujeitos mais críticos, reflexivos, autônomos, conscientes, capazes de transformarem o meio em que vivem em prol da melhoria das condições de vida.

Quando questionadas se há, por parte da escola, um trabalho voltado à integração com a comunidade onde a escola está inserida, a professora Rosa externa que procura desenvolver essa integração "trabalhando projetos que envolvam a comunidade" e a professora Violeta ressaltou que essa integração acontece nas "reuniões, palestras, culminâncias de projetos, debates". A diretora Gardênia afirmou que "da mesma forma com os pais, sempre informando de todas as atividades e eventos, convidando para a escola e delegando funções".

Atentando-se aos excertos, ao analisar como acontece a relação entre a escola e família, especialmente na EC, pressupõe a necessidade de uma junção entre o que se é trabalhado na escola e o que é repassado pela família e a vivência do aluno no meio social. Com isso, nota-se a importância da constituição de um currículo que valorize o conhecimento popular e o cotidiano das famílias campesinas, que são povos com uma vasta cultura e conhecimento singular, desenvolver a cultura local dentro da sala de aula fortalece o vínculo do aluno com suas raízes.

"E o modo de fazer a luta pela escola tem desafiado os camponeses a ocupá-la também nessa perspectiva, como sujeitos, humanos, sociais, coletivos, com a vida real e por inteiro, trazendo as contradições sociais, as potencialidades e os conflitos humanos para dentro do processo pedagógico, requerendo uma concepção de conhecimento e de estudo que trabalhe com essa vida concreta. Isso tem exigido e permitido transformações na forma da escola, cuja função social originária" deveria "fazer da vida seu princípio educativo"”' (Caldart, 2008, p. 265).

Diante dessa realidade, a escola não pode deixar de tratá-las, não pode negar o conhecimento nem mesmos os conflitos que envolvem o povo do campo, as tensões e luta por direitos, a pressão do latifúndio e do agronegócio em função dos espaços territoriais, dentre outros aspectos do cotidiano da vida de quem vive nesse espaço.

Agindo dessa maneira, a escola reconhece a sua relevância para essa comunidade e, em especial às crianças, além de se modificar, como uma continuação do que é vivenciado no ambiente familiar e social. É por essa história, construída por experiências e pelo sentido que ele dá ao mundo, que se deve estudar sua relação com o saber.

\section{Implicações da participação da família no desenvolvimento educacional dos alunos}

Ao reconhecer o sujeito como parte de um contexto das relações pessoais e sociais que vivencia durante sua vida, a análise pedagógica sobre o desenvolvimento no processo de aprendizagem escolar deve levar em consideração as relações significativas que compõem todo o seu ser social. Quando se trata da relação entre família e escola, fala-se, principalmente, na possibilidade de compartilhar critérios educativos para que possam minimizar as possíveis diferenças entre os dois ambientes.

Bourdieu (1998) e Lahire (1997) em suas pesquisas sobre o tema afirmam que, na trama social e escolar que permeia as histórias de sucesso ou fracasso, diversos fatores têm sido apontados como fundamentais. Dentre vários, alguns são destacados: a mobilização pessoal, o valor atribuído à educação pelas famílias, a ordem moral doméstica, o apoio e o esforço dos pais para entender e ajudar os filhos nos seus trabalhos escolares.

Portanto, são muitos os fatores que intervém no processo educacional da criança, o que pode resultar num baixo resultado/rendimento na análise do processo de aprendizagem. Aqui, buscou-se destacar a influência da família nesse/no desenvolvimento e aprendizado escolar. Ao serem questionados sobre essa influência no melhor desempenho do aluno, os familiares responderam que: 
"Sim. Porque ajuda eles a ter mais vontade de estudar" (Participante F).

"Como tem, é muito importante a gente trabalhar em conjunto com a escola" (Participante G).

"Na minha opinião é muito importante por que ela vai saber que eu to apoiando ela e eu cobro sempre dela" (Participante L).

A partir destas falas, os entrevistados demonstram perceber a relação família-escola com a mesma ótica norteadora desta pesquisa. Uma relação que promove um melhor desenvolvimento do processo de ensino aprendizagem. Eles defendem a importância dessa colaboração com a escola e reconhece que a família não pode deixar somente à escola a responsabilidade pela aprendizagem dos filhos, devendo implicar-se com esse processo.

De acordo com Paro (2001), quanto melhor for a parceria entre escola e família, mais positivas e significativas serão os resultados na formação do sujeito. De tal modo, o envolvimento da família com a escola tem como finalidade ajudar a reflexão de diversos aspectos didáticos e cognitivo dos seus filhos, buscando sempre melhorar o seu desempenho escolar. Ao abordar sobre essa questão, as professoras afirmaram que:

"À família cabe o papel de auxiliar as crianças na resolução das atividades, incentivo das mesmas para estudar, preocupar-se com o desenvolvimento dos filhos, comparecer às reuniões e eventos, envolvendo-se com o funcionamento da escola e comparecendo à escola regularmente para acompanhar o progresso dos seus filhos" (Professora Girassol).

"O papel da família é o de acompanhar como o aluno está na escola, cobrar para responderem às atividades $e$ sempre estar atenta como os alunos estão indo nos estudos" (Professora Rosa).

"Participar juntamente com a escola no processo de ensino aprendizagem dos filhos" (Professora Margarida).

“Acompanhar os filhos nas tarefas de casa, ser presente na escola” (Professora Violeta).

Os depoimentos das professoras apontam que a família tem um papel importante na aprendizagem dos filhos, no entanto, ressaltam que sua função vai muito além do que somente acompanhar as atividades passadas para os alunos, precisa-se também que participe ativamente das reuniões e acompanham como se desenvolvem os processos na escola.

Diante do exposto, é necessário que os pais levem em consideração que em casa também é importante reservar um local adequado para o estudo e realização de tarefas escolares. Mostrar aos filhos que é fundamental o estudo para alcançar seus objetivos, demonstrar empolgação com dada etapa vencida pela criança. É o que ressalta a diretora escolar:

"Acompanhar as crianças nas atividades de casa, participar da vida estudantil das crianças, incentivarem a frequência na escola, apoiando e acompanhando os estudantes nos eventos e participando de reuniões e atividades da escola que exijam a participação da família" (Gardênia, diretora da escola).

Percebe-se que a participação da família na educação formal engloba a necessidade de cumprir várias etapas. Compreende-se que a família deve buscar orientar e criar rotinas para os estudos, pois a tarefa de ensinar não cabe apenas à escola, embora também seja um dos seus papéis e, a partir dessa interação, que se percebe que a participação da família na escola é fundamental para o bom rendimento escolar. 
“É possível imaginar uma relação entre pais e escola que não esteja na exploração dos primeiros pela segunda. É possível imaginar um tipo de relação que não consista simplesmente de uma "Ajuda" gratuita dos pais à escola. Podese pensar em uma integração dos pais com a escola, em que ambos se apropriem de uma concepção elaborada de educação que, por um lado, é um bem cultural para ambos e, por outro, pode favorecer a educação escolar e, isso de fato, reverse em benefícios dos pais, na forma de melhoria da educação dos seus filhos" (Paro, 2007, p. 25).

É compreendido que, sendo conhecedora dessa realidade, a escola busque alternativas que possibilitem a conscientização da família sobre a importância da sua participação e construa caminhos que possam ser percorridos conjuntamente com a comunidade escolar, visando o desenvolvimento cognitivo, psicológico, afetivo do filho/aluno.

Assim, a relação da escola com a família dos alunos pode mostrar aos professores fatores que estão interferindo na aprendizagem e até mesmo apontar os caminhos mais adequados para superar esses desafios. Quando questionados sobre a existência de alguma diferença na socialização e aprendizagem das crianças conforme a participação da família no ambiente escolar, as professoras afirmaram que:

"Os alunos que as famílias são mais presentes que vem sempre nas reuniões ou vem aqui perguntar como eles estão indo na escola consegue ir melhor nas provas e sempre traz as atividades respondidas" (Professora Margarida).

"Quando os pais são presentes percebemos que as crianças são mais felizes e apresentam melhor aprendizagem, quando os pais são ausentes temos alunos mais rebeldes e menos interessados nas atividades; ou seja, a carência de afeto e atenção prejudica sua aprendizagem e relação com a escola e seus sujeitos" (Professora Violeta).

São depoimentos que elucidam o quanto a convivência e o relacionamento familiar são fatores importantes no desenvolvimento do aluno, levando em consideração que a criança que tem em casa uma família que apoia os seus estudos e valoriza a escola, tem um comportamento diferenciado no ambiente escolar.

Diante do apresentado, entende-se que não é possível buscar um entendimento amplo do aluno quando não se leva em consideração a sua vida enquanto ser social, e a sua estrutura familiar, sendo que essa organização familiar exerce influência em suas atitudes e participação na escola. Diagnóstico apresentado por Lück, ao apontar:

"a participação dos pais na vida da escola tem sido observada em pesquisas, como um dos indicadores mais significativos na determinação da qualidade do ensino, isto é, aprendem mais os alunos cujos pais participam mais da vida da escola" (Lück, 2000, p. 86).

Portanto, a partir do momento em que a escola passa a abrir espaços e criar mecanismos para atrair a família para o seu interior, novas chances aparecerão para que seja desenvolvida uma educação de qualidade, apoiada por essa parceria. Diante dessa realidade, a parceria entre escola e família deve ser vista como uma ampliação das probabilidades de acertos na educação da criança, estabelecendo uma expectativa que, através dessa dialogicidade, o aluno avance. Neste sentido, a diretora escolar sinaliza:

"Sim, é perceptível que quanto mais a familia participa do cotidiano escolar, mais seus filhos apresentam melhor nivel de aprendizagem. Com a família na escola os estudantes se sentem mais seguros, querem impressionar os pais" (Gardênia, diretora).

Esse excerto reafirma a importância dessa relação no desempenho escolar do aluno. Quando acontece essa integração, de maneira a contemplar a realidade, só tem a enriquecer e facilitar o desempenho escolar da criança. Paro (2001), ao discutir sobre o papel da família, destaca a importância do apoio dos pais aos propósitos educacionais da escola e realça “[...] que essa 
adesão precisa redundar em ações efetivas que contribuam para o bom desempenho do estudante" (Paro, 2001, p. 57). Logo, para o autor, o bom desempenho dos alunos perpassa um caminho longo no interior da própria escola, “[...] em termos da adequação de seus objetivos e de seu aparelhamento material, humano e metodológico" (Paro, 2001, p. 58).

Desse modo, para que a participação da família possibilite uma parceria efetiva e significativa, a escola deve ter no seu Projeto Político Pedagógico (PPP) ações previstas de como construir essa articulação. O PPP é o documento de maior completude na escola. Ele tem informações sobre toda a estrutura organizacional e funcionamento, no que tange aos aspectos pedagógicos, administrativos, normas de funcionamento, proposta curricular, fins, objetivos, missão, princípios norteadores. Apresenta toda a disponibilidade da escola em termos de recursos humanos e materiais. Enfim, constam todas as reais intenções da escola, sua vontade política de agir como instituição no sentido de cumprir suas finalidades. De acordo com o PPP em vigência e analisado, as metas estabelecidas, na relação entre família e escola, são:

-Promover encontros com pais alunos e professores;

-Promover momento de descontração e lazer aos professores e toda comunidade escolar;

-Respeitar a realidade dos alunos, buscando tornar a aprendizagem mais significativa;

-Oferecer momento de integração entre a família assentada no ambiente escolar;

-Aproximar os conteúdos da realidade dos alunos, propondo aulas que despertem o interesse e a curiosidade para o meio rural;

- Valorizar o esforço, a responsabilidade e a participação e não só o resultado final (Projeto Político Pedagógico, 2014, p. 9).

O documento, de caráter normativo, prevê que haja encontros com os pais dos alunos, organização de projetos, divulgação de resultados de atividades como feiras de conhecimento, manifestações artístico-culturais e outros aspectos. Importante ressaltar que não basta organizar as reuniões ou eventos. Faz-se necessário, em primeiro lugar, que tais metodologias estejam conectadas com os desejos, interesses e necessidades das famílias e, também, conecte com o processo de ensino-aprendizagem, que sejam utilizadas a favor de questões que se relacionem diretamente com o mundo cultural.

\section{Entre trilhos e caminhos: possibilidades de efetivação dessa participação}

Da mesma maneira que busca diagnosticar os problemas pedagógicos dos estudantes a fim de que possa conhecer suas dificuldades e, a partir delas, trabalhar de forma que o aluno consiga superar e assim ter uma aprendizagem qualitativa. A escola pode também buscar conhecer o ambiente familiar em que as crianças vivem e, assim, elaborar estratégias para que a família participe da vida escolar dos filhos, sempre tomando como premissa seus limites e possibilidades.

Esta parceria, caso ocorra de forma concreta, favorece o desenvolvimento das crianças na escola, uma vez que, estas relações fortalecidas proporcionam o interesse maior dos pais pelo acompanhamento da aprendizagem dos filhos.

A partir desta reflexão, foi perguntado aos familiares "Como deveria ser a relação possível entre família e escola?" Um grupo de entrevistados respondeu que não requer mudanças. No entanto, uma parte do grupo fez intervenções propositivas para que se valide, de forma efetiva, esta parceria (Quadro 5). 
Quadro 5 - Transcrições das principais intervenções na relação família-escola, de acordo com participantes.

\begin{tabular}{|c|c|}
\hline em mudanças & Sugerem mudanças \\
\hline $\begin{array}{l}\text { "Pra mim a relação minha e a escola do meu filho não } \\
\text { precisa mudar em nada acho muito boa a interação } \\
\text { entre a família e a escola" (Participante D) }\end{array}$ & $\begin{array}{l}\text { "Deveria ser mais ativa" (Participante A) } \\
\text { "Deveria ter mais dinâmicas de participação dos pais" } \\
\text { (Participante B) }\end{array}$ \\
\hline $\begin{array}{l}\text { "Eu não modificaria nada” (Participante E) } \\
\text { “Ta boa do jeito que está” (Participante F) } \\
\text { “A relação é boa” (Participante G) }\end{array}$ & $\begin{array}{l}\text { "Nós enquanto pai poderia visitar mais a escola e ajudar mais } \\
\text { nas demandas da escola, a escola poderia promover mais } \\
\text { momentos de entrosamento entre a família e a escola" } \\
\text { (Participante C) }\end{array}$ \\
\hline "Não mudaria nada!" (Participante H) & $\begin{array}{l}\text { "Participativa e ativa nas decisões" (Participante K) } \\
\text { "Eu acho que deveria que usasse uma estratégia que chamasse } \\
\text { a atenção dos pais para tá sempre na escola para saber como } \\
\text { está o seu filho" (Participante L) }\end{array}$ \\
\hline
\end{tabular}

Fonte: Autores (2021).

Diante deste diagnóstico, elaborar estratégias de acordo com o seu contexto, de forma a fortalecer cada vez mais a participação e interação dos pais. Ao final do estudo, os docentes e a diretora foram instigados a apresentar possíveis estratégias que a escola poderia elaborar para que as famílias participassem mais da vida escolar. Algumas sugestões:

"A escola poderia criar mais atividades em que os pais viessem na escola como a construção de uma horta escolar" (Professora Rosa).

"Trabalho com oficinas, continuidade do trabalho com projetos, atividades que chamem atenção dos pais" (Professora Violeta).

"Promovendo palestras com especialistas para mostrar a importância da família na escola, fazendo oficinas com pais e alunos, na organização dos eventos, nos jogos e gincanas” (Professora Girassol).

"Com palestras, oficinas para apresenta os trabalhos dos alunos realizados na escola, estarem sempre dialogando e a disposição das famílias” (Professora Margarida).

"Realização de feiras culturais com oficinas feitas pela família, abrir a escola para feiras, onde cada família traz os produtos que têm em sua propriedade” (Diretora Gardênia).

Tomando como base das falas dos entrevistados foi construído um painel integrado de desafios e possibilidades para a construção de uma parceria efetiva entre família e escola (Quadro 6). 
Quadro 6 - Desafios e possibilidades na construção da parceria entre família e escola.

\begin{tabular}{|l|l|l|}
\hline \multirow{2}{*}{ DESAFIOS } & \multicolumn{1}{|c|}{ POSSIBILIDADES } \\
\cline { 2 - 3 } Reuniões & \multicolumn{1}{|c|}{ ESCOLA } & \multicolumn{1}{|c|}{ FAMÍLIA } \\
\hline $\begin{array}{l}\text { Distanciamento } \\
\text { entre vivências }\end{array}$ & $\begin{array}{l}\text { Reconhecer as especificidades de cada aluno e } \\
\text { planejar atividades com a participação da } \\
\text { família, com foco naquilo que discuta a a } \\
\text { realidade da comunidade }\end{array}$ & $\begin{array}{l}\text { Compreender a importância da sua presença e } \\
\text { buscar participar de forma mais ativa }\end{array}$ \\
$\begin{array}{l}\text { importância de a criança valorizar a escola } \\
\text { como espaço social na construção do saber } \\
\text { científico }\end{array}$ \\
\hline $\begin{array}{l}\text { Participação nas } \\
\text { tomadas de decisões }\end{array}$ & $\begin{array}{l}\text { Propor formações que tenham como tema } \\
\text { "direitos e deveres" da família como membro } \\
\text { da gestão escolar }\end{array}$ & $\begin{array}{l}\text { Reconhecer-se como membro efetivo da gestão } \\
\text { da escola e usar esse direito na busca pela } \\
\text { efetivação de uma educação de qualidade }\end{array}$ \\
\hline $\begin{array}{l}\text { Resoluções das } \\
\text { atividades } \\
\text { extraescolares }\end{array}$ & $\begin{array}{l}\text { Elaborar atividades que as famílias consigam } \\
\text { acompanhar e ajudar nas resoluções }\end{array}$ & $\begin{array}{l}\text { Gerir o tempo para que possam acompanhar o } \\
\text { desenvolvimento da criança motivando-os a } \\
\text { responderem as atividades extraescolares }\end{array}$ \\
\hline Diálogos & $\begin{array}{l}\text { Criar canais para que a família consiga se } \\
\text { comunicar, bem como a proposição, } \\
\text { viabilização e divulgação de aplicativos de } \\
\text { celulares }\end{array}$ & $\begin{array}{l}\text { Sugerir propostas que possam complementar o } \\
\text { processo de ensino dos filhos, procurando } \\
\text { estarem sempre atentos às dificuldades que } \\
\text { possam surgir }\end{array}$ \\
\hline
\end{tabular}

Fonte: Autores (2021).

A partir deste quadro propositivo, denota-se que na relação família-escola, permeiam-se infinitas possibilidades e desafios, que requerem um olhar, especialmente por parte da escola, na difícil, mas gratificante tarefa de compreensão da realidade do público a quem atende, ou seja, a comunidade em que está inserida.

\section{Considerações Finais}

O sistema educacional deve propiciar aos alunos possibilidades de vivenciar as diferentes formas de inserção sociopolítica e cultural. Para que isso ocorra, a escola atual deve assumir-se como espaço social de construção dos significados éticos necessários e constitutivos de toda e qualquer ação de cidadania. À medida que demonstra a relevância da essência das relações que o sujeito estabelece durante a sua vida social e seu desempenho no processo de aprendizagem escolar o pensamento crítico em relação à sociedade em que vive, vislumbra novos percursos para a educação.

A pesquisa teve como objetivo analisar a implicação da parceria escola-família no desempenho escolar em uma escola situada no campo e, nesse sentido, foi possível perceber que a parceria escola e família influenciam no processo de ensino aprendizagem das crianças. $\mathrm{O}$ resultado do presente estudo evidenciou que, tanto os familiares como os docentes e a equipe gestora entendem como essencial a participação da família no processo escolar, e reconhecem a importância que a articulação entre as duas partes pode propiciar no desempenho escolar.

Percebe-se, diante desse contexto, que a família é parte fundamental no processo ensino-aprendizagem podendo interferir de maneira direta nas relações estabelecidas pelo aluno com o ambiente escolar e o ambiente social em que vive.

Partindo dessa reflexão, torna-se imprescindível que a escola, especificamente a situada no campo, busque conhecer a realidade familiar em que os alunos estão inseridos, bem como seus anseios, angústias e necessidades. Assim poderá compreender o porquê das suas principais dificuldades. Nessa perspectiva, o trabalho pedagógico precisa ser direcionado para a problematização da realidade, possibilitando a ampliação da visão de mundo do povo do campo, valorização de seus conhecimentos e reconhecimento enquanto sujeitos de direitos.

Em síntese, a relação entre a instituição escolar e a família configura-se como uma relação amistosa e de parceria, no entanto, é preciso maior engajamento das famílias na tomada de decisões da escola. No que tange essa relação, percebe-se que há duas demandas postas: de um lado, há a necessidade que a escola crie mecanismos que possibilite às famílias compreender a 
importância de participarem mais ativamente da vida escolar dos filhos, ressaltando que essas estratégias precisam ser pensadas levando em consideração, suas especificidades e anseios, respeitando o contexto sócio-político, cultural e econômico do homem campesino.

Por outro lado, há necessidade de que a família reconheça a importância dessa integração e busque meios para dedicar mais tempo no acompanhamento e proposição de atividades escolares. Para tanto, é necessário que espaços de discussão sejam fomentados, com vistas a uma participação efetiva entre, muito mais que componentes ou representantes familiares, mas, sobretudo, atores e sujeitos que tipificam cada escola, família, alunos e que, por fim, constitui uma comunidade.

Realizar este trabalho é importante, não somente por alcançar os objetivos gerais e específicos propostos, mas por promover reflexão a partir da diagnose de uma escola de campo em suas relações família-escola.

No que diz respeito à vida profissional como docente, este trabalho é um documento de contribuição, ao evidenciar que é preciso superar a visão mecânica, ainda existente, de que a educação é separada por partes. É a partir daí que se propõe uma visão sistêmica desse processo, reconhecendo que ele é constituído pela integração de todas as partes, construído a muitas mãos.

É importante ressaltar que, o presente estudo está aberto a novas reflexões, pois todo conhecimento está pautado em tempo e espaço, por isso é passível de novas necessidades, questionamentos e discussões, em prol da compreensão/soluções dos principais fatores que estão presentes na relação entre escola e família no âmbito da EC.

\section{Referências}

Ariès, P. (1981). História Social da Criança e da Família. (2a ed.), LTC.

Arroyo, M. G. (1982). Escola, Cidadania e Participação no Campo. In: Em Aberto/INEP. Brasília.1(9).

Arroyo, M. G. (1999). Educação Básica e o Movimento Social do Campo. In: Arroyo, M. G. Fernandes, B. M. A educação básica e o movimento social do campo. 2. ed. Brasília: Vozes.

Arroyo, M., Caldart, R. \& Molina, M. (org.) (2005). Por uma educação do campo. (3 ed.), Vozes.

Battaglia, M. C. L. (2002). Terapia de Família Centrada no Sistema. Conectando a Abordagem Centrada na Pessoa à Teoria Sistêmica de Família: ampliando recursos e revigorando o processo. Rio de Janeiro, UFRJ/Instituto de Psicologia, 116 p.

Brasil. Constituição Federal. (1967). Constituição da República Federativa do Brasil. Brasília: Ministério das Comunicações.

Brasil. Constituição Federal. (1988). Constituição da República Federativa do Brasil. Brasília: Ministério das Comunicações.

Brasil. Ministério da Educação. (1996). Lei de Diretrizes e Bases da Educação 9.394/96. Brasília. MEC.

Bourdieu, P. A. (1998). Escola conservadora: as desigualdades frente à escola e à cultura. In: Nogueira, MA. e Catani, A. (Orgs). Escritos de educação. Petrópolis: Vozes.

Caldart, R. S. (2002). Por uma educação do campo: traços de uma identidade em construção. In: Kolling, E. J.; Cerioli, P. R., \& Caldart, R. S. (Orgs). Educação do Campo: Identidade e Políticas Públicas. Brasília: (Coleção Por uma Educação Básica do campo, nº 4), p. 25 - 36.

Caldart, R. S. (2008). Sobre educação do campo. In: Santos, CA. dos (Org.). Educação do campo: campo - políticas públicas - educação (NEAD Especial: 10). Brasília: INCRA, MDA.

Castro, J. M., \& Regattieri, M. (Orgs.). (2009). Interação escola-família: subsídios para práticas escolares. Brasília: UNESCO, MEC. http: http://portal.mec.gov.br/index.php?option=com_docman\&view=download\&alias=4807-escola-familia-final\&Itemid=30192

Cenci, Â. V. (2000). O que é ética? Elementos em torno de uma ética geral. Editora Passo Fundo.

Coelho, L. R. S. (2011). A função Social da Escola na Educação do Campo. Lugares da Educação, 1(2), 136 - 149. https://periodicos.ufpb.br /index.php/rle/article/view/10972

Dias, J. C. (1996). A problemática da relação famílialescola e a criança com necessidades educativas especiais. Instituto Jean Piaget.

Dessen, M. A. \& Polonia, A. C. (2007). A Família e a Escola como contextos de desenvolvimento humano. Paideia, 17(36), 21 - 32. https://www.scielo.br/pdf /paidei a/v17n36/v17n36a03.pdf

Durkheim, E. (1978). Educação e Sociologia. (11a ed.), Melhoramentos. 
Fernandes, B. M. (2002). Por uma educação do campo: traços de uma identidade em construção. In: Kolling, EJ., Cerioli, PR. e Caldart, R. S. (Org). Por uma Educação do Campo: Identidade e Políticas Públicas. Brasília, p. 18 - 25.

Fernandes, B. M., Cerioli, P. R. \& Caldart, R. S. (2009). Conferência Nacional "Por uma Educação Básica do Campo". In: Arroyo, MG, Caldart, RS e Molina, MC (Org). Por uma educação do campo. (4a ed.), Vozes, p. 19 - 64.

Gil, A. C. (1987). Como elaborar projetos de pesquisa. (4a ed.), Atlas.

Gil, A. C. (2002). Métodos e técnicas de pesquisa social. (4a ed.), Atlas.

Lahire, B. (1997). Sucesso escolar nos meios populares: as razões do improvável. Ática.

Libâneo, J. C. (2004). Organização e Gestão Escolar Teoria e Prática. Goiânia: Ed. Alternativa, (5a ed.),

Lück, H. (2000). A escola participativa: o trabalho do gestor escolar. (4a ed.), DP\&A.

Ludke, M. \& André, M. E. D. A. (1986). Pesquisa em educação: abordagens qualitativas. São Paulo: EPU.

Macedo, RM. (1998). A família diante das dificuldades escolares dos filhos. In: Avaliação Psicopedagógica da criança de zero a seis anos. Vozes, p. $185-206$.

Nogueira, M. A. (2006). Família e Escola na Contemporaneidade: os meandros de uma relação. Educação e Realidade, $31(2)$, 155 - $170,2006$. https://www.redalyc.org/pdf/3172/317227044010.pdf

Oliveira, S. L. (1999). Tratado de Metodologia Científica. Pioneira.

Osório, L. C. (1996). Família Hoje. Artes Médicas.

Paro, V. H. (2001). Gestão democrática na escola pública. Ática.

Paro, V. H. (2007). Qualidade do ensino: a contribuição dos pais. Xamã.

Parolin, I. (2008). Relação Família e Escola. Revista atividades e experiências. Positivo.

Pequeno, ACA. (2005). Educação e família: uma educação fundamental?

Reis, L. P. C. (2010). A participação da família no contexto escolar. UNEB.

Ribeiro, M. (2013). Política educacional para populações camponesas: da aparência à essência. Rev. Bras. Educ. [online]. 18(54), 669 - 691. https://doi.org/10.1590/S1413-24782013000300009

Silva, E. C. R. (2012). Perspectivas do professor com relação à integração da família do educando ao ambiente escolar. Para entender a história... Ano 3 , Série $14 / 02$

Yin, R. K. (2005). Estudo de Caso: Planejamento e Métodos. Trad. Daniel Grassi. (2a ed.), Bookman. 